\title{
Within-signal learning in autoshaping
}

\author{
ROBERT A. RESCORLA \\ Yale University, New Haven, Connecticut 06520
}

\begin{abstract}
Four experiments explored the formation of associations among elements of a compound visual CS in an autoshaping preparation using pigeon subjects. Experiment 1 found evidence for such associations when the compound was presented without food reinforcement. Experiments 2 and 3 demonstrated that compounds embedded in procedures that produce blocking and conditioned inhibition also developed associations among their elements. Experiment 4 found, using a conditional discrimination procedure, that such within-signal associations were weakened, but not eliminated, by the presentation of food reinforcement at the end of the compound. These results suggest a pervasive role for within-signal associations across a variety of conditioning procedures that have been given central roles in current theories of conditioning.
\end{abstract}

Most studies of Pavlovian conditioning have concentrated on the formation of associations between two separately presented stimuli. In the typical case, one of those stimuli, the conditioned stimulus (CS), signals the occurrence of the other, the unconditioned stimulus (US). However, we have recently reported that associations are also formed among the elements within each of these stimuli. The evidence is especially strong for the case of CSs that have identifiable separate elements (e.g., Rescorla \& Cunningham, 1978; Rescorla \& Freberg, 1978; Speers, Gillan, \& Rescorla, 1980). Most of that evidence comes from experiments using a flavor-aversion preparation, in which the $\mathrm{CS}$ is a flavored liquid; but, within-CS associations have also been described for conditioned suppression, in which the CS is composed of auditory and visual elements (e.g., Rescorla, 1980).

The present experiments had two purposes-first, to extend these observations to another preparation, autoshaping with visual stimuli in pigeons, and, second, to examine the interaction of associations within the CS and those between the CS and US. The first experiment simply demonstrated within-CS associations in an autoshaping setting using a sensory preconditioning design like that of Rescorla and Cunningham (1978). Experiments 2 and 3 examined whether such within-CS learning occurs in the context of two standard compound stimulus paradigms, blocking and conditioned inhibition. Speers et al. (1980) found evidence for such associations using a flavor-aversion procedure, but were unable to demonstrate simultaneously the occurrence of the normally expected blocking and conditioned inhibition outcomes. The present experiments document the oc-

This research was supported by NSF Grant BNS 78-02752. Thanks are due to Paula Durlach for many helpful comments. Requests for reprints should be sent to Robert A. Rescorla, Department of Psychology, University of Pennsylvania, 3815 Walnut Street, Philadelphia, Pennsylvania 19104. currence of blocking and conditioned inhibition, and, at the same time, they detect associations between the CSs used to generate those outcomes.

Finally, Experiment 4 used a conditional discrimination to examine the interaction between associations among CSs and those between the CS and US. Pavlovian paradigms that involve the presentation of compound stimuli differ in the degree to which those compounds are themselves followed by a US. It is thus of interest to inquire whether the magnitude of the within-CS association is affected by the occurrence of the US after the CS.

\section{EXPERIMENT 1}

This experiment used the sensory preconditioning design of Rescorla and Cunningham (1978) to explore associations among the components of a compound visual stimulus. Initially, pigeons were exposed to two compound stimuli, each consisting of a color and a line orientation. Then, one of the orientations was paired with food in an autoshaping procedure, resulting in directed pecking at that orientation. Finally, responding to the colors was tested. Evidence for the occurrence of within-compound associations would take the form of greater test responding to that color whose paired orientation was subsequently reinforced with food.

\footnotetext{
Method

Subjects and Apparatus. The subjects were 16 female Carneaux pigeons about 1 year old, maintained at $75 \%$ of their free-feeding weights. They had previously participated in a second-order autoshaping experiment that used a response key and stimuli different from those employed here. Treatments in the present experiment were arranged to be orthogonal to those experimental histories.

The apparatus was eight identical operant chambers, each measuring $27 \times 27 \times 35 \mathrm{~cm}$. The metal front panel of each chamber had a $5 \times 5 \mathrm{~cm}$ food magazine in its center, located $5 \mathrm{~cm}$ above the wire-mesh floor. There were three response keys, $2.5 \mathrm{~cm}$ in diameter-one was located directly above the hopper and one was
} 
located on either side of the center of the front wall, $20 \mathrm{~cm}$ above the floor. Located behind the right-hand key was an IEE in-line projector that permitted the transillumination of the key with color and orientation stimuli. The lower half of that key could be illuminated with either blue (B) or yellow (Y) light; the upper half could be illuminated by one of two grids that differed in both orientation and line width. One grid consisted of 1 -mm black lines spaced $2 \mathrm{~mm}$ apart on a white background and oriented $45 \mathrm{deg}$ from the vertical; the other grid consisted of $1-\mathrm{mm}$ black lines spaced $1 \mathrm{~mm}$ apart on a white background and oriented $-45 \mathrm{deg}$ from the vertical. When only a color or orientation was presented, the other half of the key remained black. When compounds were presented, a $1-\mathrm{mm}$ black line separated the components. These stimuli were generated by Ektachrome slides of drawings composed of "Color-aid" artists" paper. In addition, the entire key could be illuminated by a uniform white stimulus. The remaining walls and ceilings of the chambers were composed of clear Plexiglas.

These chambers were placed in sound-and light-attenuating shells with ventilation fans providing background noise. On the rear wall of these shells was mounted a $6-\mathrm{W}$ bulb that was continuously illuminated during the session, except during the operation of the food hopper. The hopper contained Purina Pigeon Grain.

Procedure. Because these birds had previously received autoshaping training in another experiment, no magazine experience was necessary. However, to ensure a uniform level of orientation toward the front panel, all birds initially received two sessions in which the full-key white stimulus was paired with food. On each day, the birds received 60 pairings of a $5-\mathrm{sec}$ white key with $5-\mathrm{sec}$ access to grain. The intertrial interval was variable around a mean of $1 \mathrm{~min}$.

On the next 3 days, the birds were exposed to two of the colororientation compounds. On each day, the birds received 12 nonreinforced presentations of each of two compounds. For half of the birds, the compounds were blue $/ 45 \mathrm{deg}$ and yellow/ $-45 \mathrm{deg}$; for the remaining birds, the alternative compounds were presented. In addition, in order to maintain the birds' orientation toward the front of the chamber and to encourage observation of these compounds, each bird received six reinforced presentations of the full-key white stimulus intermixed with these compound presentations. All stimulus durations were $5 \mathrm{sec}$, and trials occurred on the average of once a minute.

During each of the next three sessions, an attempt was made to condition one of the orientations while presenting the other without reinforcement. On each day, the birds received 12 presentations of each orientation. The occurrence of one orientation was followed by $5 \mathrm{sec}$ of food. For half the birds, that orientation previously paired with blue was reinforced, whereas that previously paired with yellow was nonreinforced; for the remaining birds, the reinforcement contingencies were reversed.

On the next day, a single nonreinforced test session was given with blue and yellow. The first half of that session was identical to the first half of the previous three sessions. During the second half, each bird received six nonreinforced presentations of blue and yellow, spaced $1 \mathrm{~min}$ apart.

\section{Results and Discussion}

The birds rapidly developed responding to the white key during the initial phase of the experiment. However, they showed little sign of generalization of that responding to the compound stimuli. Over the course of the 3 days of exposure to the compounds, the mean response rate to the compounds was $3 / \mathrm{min}$, whereas that to the white key was 44 responses/min. The subsequent discrimination between the two orientations was also quite rapid. By the final day of this training, the mean response rate during the rein- forced orientation was 76 responses/min, whereas that during the nonreinforced orientation was $3 / \mathrm{min}$.

The results of greatest interest are from the final testing of the colors. The mean response rate to that color whose paired orientations was subsequently reinforced was 26 responses/min; that to the color whose paired orientation had been nonreinforced was 11 responses $/ \mathrm{min}$. The greater responding to the former color [Wilcoxon $T(13)=5, p<.01$ ] suggests that associations had indeed been formed between the orientations and their paired colors. Responding to the colors was dependent upon the current conditioning of the orientations with which they had been paired. This provides evidence for associations among components of a visual CS analogous to those among components of a flavor CS demonstrated by Rescorla and Cunningham (1978).

\section{EXPERIMENT 2}

Many commonly used Pavlovian paradigms employ compound stimuli. It is, then, of interest to ask whether the modes of presentation used in those paradigms also encourage the development of associations between elements of the compound. Experiment 2 explored that possibility for one popular and theoretically important paradigm, the blocking procedure. In a typical blocking experiment (e.g., Kamin, 1968), a compound stimulus, $A B$, is followed by a reinforcer. However, for some animals, that pairing is preceded by trials on which $\mathrm{A}$ alone is followed by the same reinforcer. A frequent finding is that such pretraining with $\mathbf{A}$ reduces the conditioning gained by $B$ on the $A B+$ trials. Apparently, the occurrence of the well-conditioned A blocks the formation of an association between $B$ and the US. The question concerning the present experiment is whether, under these circumstances, $\mathrm{A}$ and $\mathrm{B}$ also become associated with each other.

\section{Method}

Subjects and Apparatus. The subjects were 16 female Carneaux pigeons about 1 year old and were maintained at $75 \%$ of their free-feeding weights. They had previously participated in a secondorder autoshaping experiment that used a response key and stimuli different from those employed here. Their assignment to groups was arranged to be orthogonal to their past experimental treatments. The apparatus was that of Experiment 1.

Procedure. On the first 2 days of the experiment, all birds received 605 -sec presentations of the white key, each followed immediately by $5 \mathrm{sec}$ of access to grain. These trials were separated by a variable intertrial interval with a mean of $1 \mathrm{~min}$.

Group $I(n=8)$ then received a treatment designed to demonstrate blocking. Their treatment is outlined in Table 1 . On the first 3 days, they received a discrimination procedure in which each orientation was presented 12 times. For half the birds, the 45 -deg orientation was reinforced with food and the -45 -deg orientation was nonreinforced; for the other half, the reinforcement contingencies were reversed. On the next 3 days, the birds received blue and yellow, each compounded with one of the orientations. On each day, they received 12 presentations of each of two com- 
Table 1

Design of Experiment 2

\begin{tabular}{ccccc}
\hline Group & Phase 1 & Phase 2 & Phase 3 & Test \\
\hline 1 & $\mathrm{O} 1+, \mathrm{O} 2-$ & $\mathrm{O} 1 \mathrm{C} 1+, \mathrm{O} 2 \mathrm{C} 2+$ & Omitted & $\mathrm{C} 1, \mathrm{C} 2$ \\
2 & $\mathrm{O} 1+, \mathrm{O} 2+$ & $\mathrm{O} 1 \mathrm{C} 1+, \mathrm{O} 2 \mathrm{C} 2+$ & $\mathrm{O} 1+, \mathrm{O} 2-$ & $\mathrm{C} 1, \mathrm{C} 2$ \\
\hline
\end{tabular}

Note- $\mathrm{Ol}$ and $\mathrm{O} 2$ are line orientations, $\mathrm{Cl}$ and $\mathrm{C2}$ are colors, and "+ "and "- " indicate reinforcement and nonreinforcement, respectively.

pounds, each followed by food. The pairings of color and orientation were counterbalanced across animals but consistent for any given animal.

On the next day, each animal received 12 nonreinforced test presentations of $\mathrm{Y}$ and $\mathrm{B}$. Notice that both colors had been followed by food when presented jointly with an orientation. However, for each animal, one color (C1) had been reinforced in the presence of a previously conditioned orientation $(\mathrm{O} 1)$, whereas the other color $(\mathrm{C} 2)$ had received identical reinforcement in the presence of a previously nonreinforced orientation (O2). Blocking would be evident as a greater level of responding for the latter color (C2).

Group $2(n=8)$ received a related sequence of treatments, designed to detect color-orientation associations. These animals were treated identically to those of Group 1 with two exceptions. First, they received an initial 3 days of training with the orientations arranged for food reinforcement to follow both orientations. They then received 3 days of training, on each day of which 12 reinforced presentations of two color-orientation compounds were given. Second, prior to the separate testing of the color stimuli, they received a discrimination procedure intended to give the orientations different values. On each of 3 days, they received 12 reinforced and 48 nonreinforced presentations, respectively, of the two orientations. They then received a test session that contained 12 nonreinforced presentations of each of the colors. Evidence for color-orientation associations would take the form of greater responding to the color that had been presented with the subsequently reinforced orientation. Those associations would have been formed under a procedure expected to produce blocking in Group 1.

Following their initial test for blocking, the animals in Group 1 were also given the Phase 3 discrimination and test procedures administered to Group 2. That is, they received reinforcement with one orientation and extinction of the other and were then treated for the consequences of those treatments upon responding to the colors. For half the animals, the originally reinforced orientation continued to be reinforced; for the other half, it was extinguished. Of interest here is whether the same animals that had been found to exhibit blocking of the association between color and food could also be shown to have color-orientation associations.

\section{Results and Discussion}

The animals in Group 1 showed rapid development of differential responding to the two orientations during Phase 1. On the final day of that phase, they responded at a mean level of $7 \dot{4}$ and 11 responses/ min, respectively, to the reinforced and nonreinforced stimuli. Responding to the reinforced colororientation compounds during Phase 2 likewise developed rapidly. By the end of this phase, response rates were not differential to the compounds and were at a mean level of 58 responses $/ \mathrm{min}$.

The results of greatest interest, from the nonreinforced test presentations of blue and yellow, are shown in the left-hand panel of Figure 1. The response rate during the color that had been reinforced in compound with a previously nonreinforced orientation is labeled $\overline{\mathrm{B}}$, for "not blocked"; that during the color that had been reinforced in compound with a previously conditioned orientation is labeled $B$, for "blocked." The greater responding for $\bar{B}$ than for $B$ represents a variation in the conditioning of the color dependent upon the prior treatment of its jointly presented orientation. That reliable difference [Wilcoxon $T(8)=2, p<.05$ ] indicates successful blocking.

The animals in Group 2, which received reinforced presentations of both orientations in Phase 1, developed responding to those orientations to a level of 50 responses $/ \mathrm{min}$ on the final day. That rate rose slightly to 68 responses/min by the end of conditioning of the color-orientation compounds in Phase 2. As a result of subsequent differential conditioning of the orientations in Phase 3, the mean rate during the reinforced orientation rose to $88 / \mathrm{min}$, whereas the mean rate during the nonreinforced orientation declined to 17 responses/min. The results of the subsequent test presentations of the colors are shown in the middle panel of Figure 1. During that test, the level of responding was higher for that color whose previously paired orientation had subsequently been reinforced (labeled + ), compared with that for a color whose orientation had been nonreinforced $(-)$ [Wilcoxon $T(8)=3, p<.05$ ]. That outcome indicates the formation of a color-orientation association in Group 2.

After their initial test, the animals in Group 1 were subjected to the same Phase 3 discrimination treatment between orientations as had been given to Group 2 and were then retested with the colors. The results of that test are shown in the final panel of Fig-

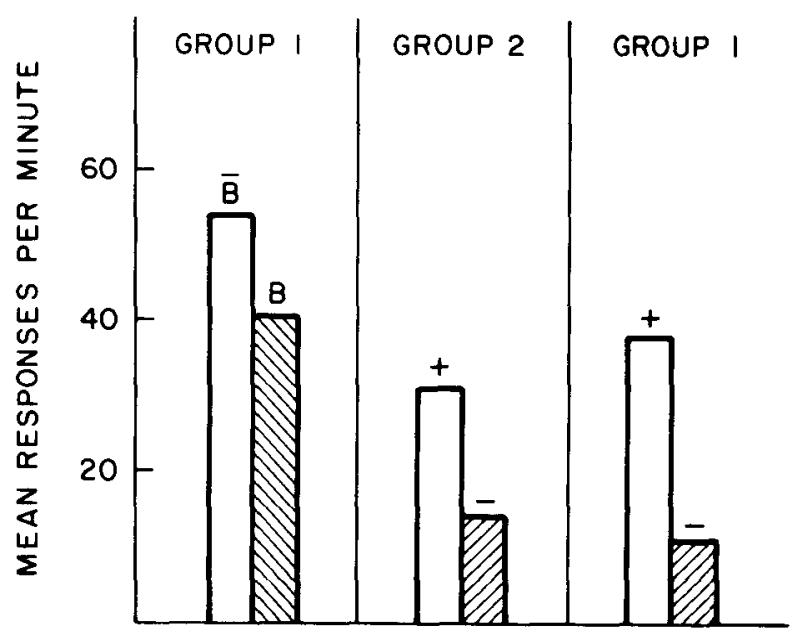

Figure 1. Mean responses per minute to the color stimuli during the test sessions of Experiment 2. A "B" indicates a color to which conditioning should be blocked; $a$ " $\bar{B}$ " indicates a color to which conditioning should not be blocked. The "+" and " - " indicate colors for which the paired orientation was subsequently reinforced and nonreinforced, respectively. 
ure 1. The current level of responding to the color was greater when its paired orientation had been subjected to the reinforced treatment of the discrimination $[T(8)=3, p<.05]$. That data pattern was found, regardless of whether that color had previously received the blocking or control treatment in the earlier phase of the experiment.

These data indicate both the occurrence of blocking of the color-food association in Group 1 and the presence of color-orientation associations under comparable conditions in Group 2. Moreover, the final test results with Group 1 suggest that the very animals that had previously shown evidence of blocking also developed associations between the colors and orientations.

It is worth commenting that the design employed here to demonstrate blocking is somewhat more elaborate than that often used. Through the use of a within-subjects design, it is possible to conduct both the blocking and control treatments in the same animals, thus guaranteeing comparable experiences with the reinforcer and with conditioning of some stimuli by that reinforcer. Many other blocking designs confound with blocking and control treatments differential experience either with the reinforcer or with conditioning per se. Perhaps the present separation of those variables is responsible for the relatively small magnitude of the blocking effect observed here. Alternatively, the substantial level of association between orientation and color may also have reduced the opportunity to observe blocking of the color-food association, since some of the responding to the color may arise from its association with the well-conditioned orientation. In this regard, one way to think about the difference in responding to the colors in Group 2 is as a demonstration that the magnitude of blocking of Stimulus B is enhanced when the originally trained A stimulus is extinguished prior to testing of $B$.

\section{EXPERIMENT 3}

This experiment explored another frequently studied Pavlovian paradigm that arranges for concurrent presentation of multiple stimuli, the conditioned inhibition paradigm. In a standard conditioned inhibition procedure, one stimulus, $\mathbf{A}$, is reinforced when presented alone but nonreinforced when presented in conjunction with another stimulus, $B$. The typical consequence of such an $\mathrm{A}+/ \mathrm{AB}-$ treatment is that A becomes excitatory, whereas $B$ becomes inhibitory, in the sense of being able to attenuate the normal excitatory response to $\mathrm{A}$. The question raised here is whether B not only becomes an inhibitor with respect to the reinforcer, but also becomes associated with the excitatory A. Speers et al. (1980) reported such a result for the flavor-aversion preparation; the present
Table 2

Design of Experiment 3

\begin{tabular}{rrrr}
$\mathrm{O} 1+, \mathrm{O} 2+$ & $\mathrm{O} 1+, \mathrm{O} 1 \mathrm{C} 1-$ & $\mathrm{O} 1+, \mathrm{O} 2-$ & $\mathrm{C} 1+$ \\
$\mathrm{O} 2+, \mathrm{O} 2 \mathrm{C} 2-$ & $\mathrm{O} 1-, \mathrm{O} 2+$ & $\mathrm{C} 2+$ \\
\hline
\end{tabular}

Note- $\mathrm{OI}$ and $\mathrm{O} 2$ are line orientations, $\mathrm{Cl}$ and $\mathrm{C} 2$ are colors, and "+" and "-" are reinforcement and nonreinforcement, respectively.

experiment employed a similar design with an autoshaping preparation.

The design entailed using two different excitors and two different inhibitors, each presented according to the $\mathrm{A}+/ \mathrm{AB}-$ procedure. However, the experiment imposed the further constraint that a particular inhibitor only appear in conjunction with one of the excitors. After the development of inhibition, one of the excitors was then extinguished, and the other received additional reinforcement. Then an attempt was made to condition excitation to both inhibitors. Evidence of an A-B association would take the form of the inhibitory $B$ being more readily trained as an excitor when the excitatory strength of its associated $\mathbf{A}$ had been maintained rather than extinguished.

\section{Method}

Subjects and Apparatus. The subjects were 16 female Carneaux pigeons with histories similar to those of the birds in previous experiments and were maintained like those birds. The apparatus was that of Experiment 1.

Procedure. The experimental design is outlined in Table 2 . Al birds first received excitatory autoshaping with the two orientation stimuli. On each of 3 days, they received $305-\mathrm{sec}$ reinforced presentations each of the 45-deg and -45-deg stimuli, projected on the top half of the right-hand response key. The intertrial interval was variable around a mean of $1 \mathrm{~min}$.

On each of the next 10 days, all animals received conditioned inhibition training. Each session contained 6 reinforced presentations of each of the orientation stimuli and 24 nonreinforced presentations of each of two color-orientation compounds. The pairings of colors with orientations were balanced across the 16 animals, but, for any one animal, each color was consistently nonreinforced in conjunction with one orientation. All stimulus durations were $5 \mathrm{sec}$, and the mean intertrial interval was $1 \mathrm{~min}$.

On the next 3 days, the animals received discrimination training intended to endow the orientations with different levels of excitation. Each animal received 12 reinforced presentations of one orientation and 48 nonreinforced presentations of the other. For half the animals, the reinforced orientation was $45 \mathrm{deg}$; for the other half, it was -45 deg.

On the next day, all animals received a test session. This session began with 6 reinforced and 24 nonreinforced presentations of the orientations, as applied on the preceding 3 days. During the remainder of the session, each animal received 15 reinforced presentations, each of blue and yellow, presented at a mean intertrial interval of $1 \mathrm{~min}$. The rates of acquisition of responding to these colors constitute the data of primary interest.

\section{Results and Discussion}

During the initial day of conditioned inhibition training, the animals responded at a mean of 55 responses/min during the reinforced orientations. 
The colors produced some initial disruption, so that the mean rate during the color-orientation compounds was 44 responses/min in this session; however, that disruption was not significant. By the final day of conditioned inhibition training, however, there was little responding during the compounds. The mean response rate during the orientations alone was $56 \mathrm{~min}$, whereas that during the compounds was $4 / \mathrm{min}$. This difference, which indicates the inhibitory power of the colors, was evident in every animal.

Despite the initial high level of responding to the orientations alone, discrimination between the orientations was rapid. By the final day of this training, the animals responded at a mean of 76 responses/min during the reinforced orientation and only 8 responses/min during the nonreinforced orientation.

The data of greatest interest, from the final test, are shown in Figure 2. That figure displays the course of acquisition of responding to the two colors, separated according to the previous treatments of their paired orientations. Both stimuli seemed to acquire excitation reasonably rapidly; however, that acquisition was faster for those stimuli whose paired orientation was not extinguished. Over the session as a whole, that stimulus showed reliably higher levels of responding $[\mathrm{T}(16)=27, \mathrm{p}<.05]$. These results suggest that, over the course of conditioned inhibition training, an inhibitor becomes associated with its paired excitor.

One implication of these findings is that, in some instances, the presence of an association with an ex-

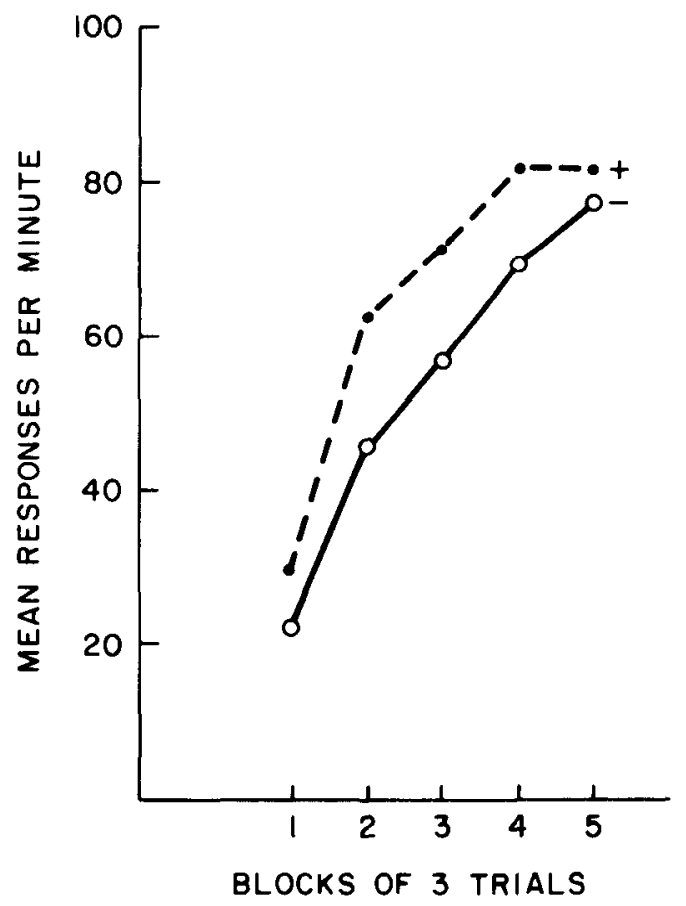

Figure 2. Mean responses per minute to the color stimuli during the reinforced test session of Experiment 3. $A+\cdots$ indicates a color whose paired excitor had subsequently been reinforced; a ". - " indicates a color whose paired excitor had been extinguished. citatory CS may cause us to underestimate the strength of an inhibitor's association with the US. For instance, it seems possible that the failure of an inhibitor to transfer fully from the excitor in the presence of which it was nonreinforced to another excitor could be due to this association. Similarly, separately presented inhibitors may fail to display fully their inhibitory association with the US if they also have an excitatory association with an excitatory CS.

Although such comparisons are difficult to make, the magnitude of the association observed here seems somewhat smaller than that seen in Experiments 1 and 2 . That apparently weaker association may be due to the different assessment procedure used in the present experiment. Alternatively, it may reflect the greater frequency of separate presentation of the excitors necessitated by the relatively slow acquisition of inhibition. Such separate presentations are known to attenuate the ability to observe associations between otherwise concurrently presented stimuli (e.g., Rescorla \& Freberg, 1978).

In the present experiment, the only evidence that the colors actually acquired inhibitory power comes from the development of a discrimination between the orientations presented alone and their presentation in compound with the colors. It is possible, of course, that such a discrimination is accomplished in ways other than by the colors becoming inhibitors. However, unpublished studies in our laboratory have found that colors treated in this way transfer their inhibition to new excitors and are retarded relative to untreated stimuli when they are subsequently reinforced. Consequently, this experiment seems to indicate that a stimulus can become a conditioned inhibitor with respect to the US and yet have an excitatory association with the excitor responsible for establishing that inhibition.

\section{EXPERIMENT 4}

The previous experiments have indicated that associations occur between concurrently presented stimuli in a variety of Pavlovian paradigms. Apparently, they occur whether the stimuli that are associated are themselves neutral, inhibitory, or excitatory. Moreover, they occur whether the consequence of compound presentation is reinforcement or nonreinforcement.

Experiment 4 addressed the more subtle issue of the conditions that modulate the magnitude of these associations. In particular, it was concerned with the effect of the trial outcome upon the magnitude of the association. Although associations between components appear to occur whether or not the trial is reinforced, there are various theoretical reasons for anticipating that reinforcement may affect the magnitude of those associations.

Two alternative possibilities seem plausible. On the one hand, currently popular notions of limited- 
capacity processing might anticipate that reinforcement following the trial would interfere with the formation of the between-component associations (see Cheatle \& Rudy, 1978; Holland, 1980; Wagner, 1978). On the other hand, many classical notions of learning have favored the position that a reinforcer that follows a contiguity between two events acts to promote the formation of an association between those events (e.g., Hull, 1943). That po tion has been advanced most frequently when the events are an external stimulus and the animal's response, but, it seems naturally extendable to the case of two stimulus events.

Any attempt to assess the strength of the betweenelement associations using procedures like those adopted here must attend to an important technical problem. Differences observed in responding to an element must be clearly attributable to differences in the strength of its association with another element rather than to its own association with the reinforcer. For instance, if one stimulus compound were followed by a reinforcer and the other were not, then any differences in the within-signal associations would necessarily be confounded with potential differences in the direct conditioning of the elements by the reinforcer. One way to deal with this confounding is to arrange for the same stimulus element to be present in two compounds, but to have only one of those compounds followed by reinforcement. One may ask whether that common element is better associated with the element with which it was compounded and then reinforced or with the element with which it was compounded and nonreinforced. But, in both cases, the tested element has had the same relation to the original reinforcer.

An autoshaping experiment reported by Rescorla and Durlach (in press) used a strategy of this sort. Animals were initially presented with trials of the form $\mathrm{AB}+$ and $\mathrm{AC}-$. Then half the animals received a further discrimination of the form $\mathrm{B}+, \mathrm{C}-$ and were tested for their response to $\mathrm{A}$. For those animals, the test should reveal the strength of the A-B association. The other animals received the reverse discrimination, $\mathrm{B}-, \mathrm{C}+$, and were then tested with $A$ to reveal the strength of the $A-C$ association. For all animals, A had previously been reinforced the same number of times under the same circumstances; therefore, the strength of the A-US association should be similar in both groups. Any differences in responding to $A$ could then be attributed to the differential strength of its associations with B and C. Rescorla and Durlach (in press) found greater within-signal learning in the nonreinforced $(A C)$ than in the reinforced $(\mathrm{AB})$ compound.

However, although such a design matches the animals for potential associations between $\mathbf{A}$ and food, it leaves them unmatched in ways that complicate interpretation. Notice that the animals receiving $\mathrm{B}-$,
$\mathrm{C}+$ training had to reverse the learning that $\mathrm{B}$ and $C$ had previously undergone. However, those animals that received $\mathrm{B}+, \mathrm{C}$ - training had no such reversal. It seems possible that reversing a discrimination leads to a generally higher level of responding that inflates responding to $\mathrm{A}$.

Experiment 4 employed a somewhat more complicated design that avoids this difficulty. All animals were initially taught a conditional discrimination of the form $\mathrm{AC}+, \mathrm{BD}+, \mathrm{AD}-, \mathrm{BC}-$. In such a design, $A$ and $B$ are equivalent with respect to their pairing with the reinforcer. Also, A and B are each presented in compound with both $C$ and $D$. However, when $A$ is presented with $C$, their conjunction is reinforced, whereas when it is presented with $D$, the conjunction is nonreinforced. Conversely, when $B$ is presented with $C$, the conjunction is nonreinforced, whereas when it is presented with $D$, the conjunction is reinforced. Of course, birds readily learn such conditional discriminations. But in the present context, the question of interest is whether the differential reinforcement will affect the development of the between-element associations. For instance, will $A$ be better associated with $D$ than with $C$, and will $B$ be better associated with $C$ than with $D$, as would be expected if reinforcement interferes with the between-element associations? In order to address that question, half the animals received a subsequent discrimination of the form $\mathrm{C}+, \mathrm{D}-$, and half received one of the form $C-, D+$; then all animals were tested for responding to $A$ and $B$. If betweenelement associations are better formed in the absence of ultimate reinforcement, then the $\mathrm{C}+, \mathrm{D}$ - discrimination should yield more responding to $\mathrm{B}$ than to $\mathrm{A}$, whereas the $C-, D+$ discrimination should yield more responding to $\mathrm{A}$ than to $\mathrm{B}$.

\footnotetext{
Method

Subjects and Apparatus. The subjects were 16 female Carneaux pigeons with histories similar to those of previous animals and were maintained as in past experiments. The apparatus consisted of four operant chambers identical in all essentials to those used in the previous experiments. The stimuli were projected on the right-hand response key. These stimuli consisted of the illumination of quadrants of the key outlined by two orthogonal black lines $1 \mathrm{~mm}$ thick that formed an "X" on the key. Two colors, orange $(O)$ and magenta $(M)$, could be projected on the left- and right-hand quadrants simultaneously. Two different patterns could be projected on the top and bottom quadrants simultaneously. Those patterns were black dots (D), .5 mm in diameter and spaced $1 \mathrm{~mm}$ apart in both the horizontal and vertical dimensions, and a set of miniature sine waves (S), about $2 \mathrm{~mm}$ long and spaced about $1.5 \mathrm{~mm}$ apart. Both patterns were projected on otherwise white quadrants. When either the colors or patterns were presented alone, the remaining quadrants were black; when they were presented together, 1-mm lines separated the quadrants.

Procedure. Initially, all animals received 3 days of simple autoshaping with an illumination of the full key with white light as the stimulus. Each session contained 605 -sec stimuli, each terminating in $5 \mathrm{sec}$ of food availability. The mean intertrial interval was $1 \mathrm{~min}$.

On each of the next 4 days, the animals received a configural discrimination. There were 12 presentations of each of 4 trial types
} 
each day. Each trial type was composed of a compound stimulus containing one color [orange $(\mathrm{O})$ or magenta $(\mathrm{M})]$ and one pattern [dot (D) or sine wave (S)]. For half the animals, the MD and OS compounds were reinforced, whereas the OD and MS compounds were nonreinforced. For the other half of the animals, the reinforcement contingencies were reversed. Reinforcement consisted of $5 \mathrm{sec}$ of grain availability; the intertrial interval was $1 \mathrm{~min}$.

On each of the next 4 days, the animals were taught a discrimination between the patterns. Each session contained 12 reinforced presentations of one pattern and 48 nonreinforced presentations of the other. For half of the animals, with each reinforcement contingency during the conditional discrimination, $S$ was reinforced and D was nonreinforced. For the other half, the reverse discrimination was given.

On the next day, all animals received continued pattern discrimination for 3 reinforced and 12 nonreinforced trials; they then received 12 nonreinforced presentations of each of the colors. It is the responding to those colors that constitutes the data of primary interest.

\section{Results and Discussion}

Despite its complexity, the conditional discrimination itself was rapidly learned. By the 4 th day of such training, the mean response rate during the reinforced compounds was 61 responses/min, whereas that during the nonreinforced compounds was $6 / \mathrm{min}$ $[T(16)=2, p<.01]$. Similarly, the subsequent discrimination between the patterns was rapid. The mean level of responding to the reinforced pattern on the final day of that discrimination was 40 responses/ $\min$; that to the nonreinforced pattern was $6 / \mathrm{min}$.

The data of primary interest, from the test presentations of the two colors, are shown in Figure 3, which displays the rates of responding over the course of extinction testing with the colors, in successive blocks of three test trials. Responding to that color that had received nonreinforced presentations with the subsequently reinforced pattern is identified by " - "; responding to that color that had received reinforced conjunctions with the subsequently reinforced pattern is identified by " + ." For instance, following an $\mathrm{AC}+, \mathrm{BD}+, \mathrm{AD}-, \mathrm{BC}-$ discrimination and subsequent $\mathrm{C}+, \mathrm{D}-$ training, the stimulus B would be labeled " - " and the stimulus A would be labeled "+." It is clear that, throughout the course of extinction testing, there was a higher level of responding to the stimuli that had been nonreinforced when paired with the presently valuable pattern $[T(16)=16, p<.05]$. Consequently, the results of this experiment are in agreement with those of Rescorla and Durlach (in press). Terminating a compound presentation in reinforcement appears to hinder the development of an association between the elements of that compound. Such an outcome supports the notion of a limited capacity that induces a competition between CS-US and CS-CS associations. In that regard, these data agree with the results from related second-order conditioning experiments reported by Cheatle and Rudy (1978) and Holland (1980). In those experiments, following a secondorder conditioning trial by a primary reinforcer at-

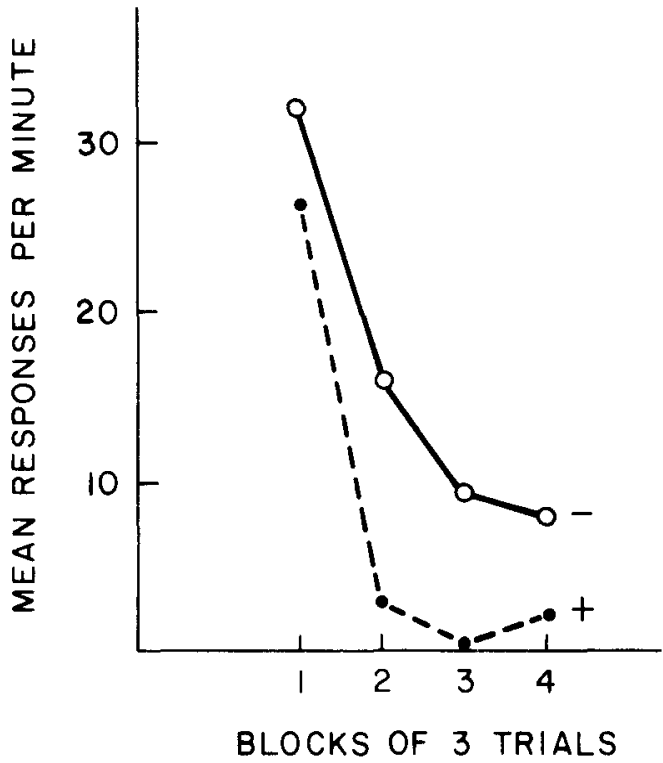

Figure 3. Mean responses per minute to the color stimuli during the extinction test session of Experiment 4. $A$ " +" indicates the color that had been paired with the pattern on reinforced trials; a "- " indicates the color that had been paired with the pattern on nonreinforced trials.

tenuated the amount of conditioning of one CS by another.

\section{GENERAL DISCUSSION}

These experiments have found evidence for the occurrence of associations among the elements of a simultaneously presented visual compound in an autoshaping situation. Moreover, they found those associations to be present with either reinforcement or nonreinforcement of the compound and when the elements themselves were neutral, excitatory, or inhibitory. These results confirm those of earlier experiments with flavor aversion and conditioned suppression preparations (Rescorla, in press; Speers et al., 1980). Moreover, the present experiments were able to document the occurrence of such associations within experiments that also produce such standard Pavlovian phenomena as conditioned inhibition, blocking and conditional discriminations. Finally, they show some evidence for an interaction between the associations among CS elements and associations between the CS and US. Apparently, circumstances that arrange for the latter association to be strong attenuate (but do not prevent) the development of associations among CS elements.

The generality of associations among elements of a compound may substantially complicate the analysis of the results of many Pavlovian experiments. Experiments attempting to analyze phenomena such as blocking and overshadowing typically arrange for the separate test presentations of one of the elements of 
a compound following some joint presentation. The results of those test presentations are frequently interpreted in terms of the strength of one element's association with the reinforcer. But the present experiments amply demonstrate that the association of one element with another may also influence performance. Consequently, manipulations that appear to modulate the magnitude of conditioned inhibition or blocking might in fact frequently have their impact upon the between-element association rather than upon the CS-US association.

One particularly striking example of such an outcome has been reported by Durlach and Rescorla (1980). Elaborating upon reports by Clarke, Westbrook, and Irwin (1979) and Rusiniak, Hankins, Garcia, and Brett (1979), they investigated a phenomenon that is apparently the opposite of overshadowing. They found that the magnitude of conditioning of an odor CS by a poisoning US was greater when that odor was accompanied by a taste on the conditioning trial. One interpretation of this finding is that the presence of the taste potentiated the association between the odor and the poison. However, Durlach and Rescorla (1980) found this apparent potentiation to be attributable instead to the association between the odor and taste. In this case, the betweenelement association was sufficiently strong to reverse the normally reported phenomenon of overshadowing. This dramatically illustrates the danger of interpreting the response to a separately presented element solely in terms of its association with the US.

The present demonstrations of between-element associations among CS elements have a parallel in learning about reinforcers. In several recent autoshaping experiments, Rescorla (1980) has shown that when a reinforcer has multiple separable elements, those elements also become associated with one another. Consequently, the generality of such learning among simultaneously presented stimuli may be quite substantial. The understanding of the rules for such learning then becomes an important goal for students of associative learning.

\section{REFERENCES}

Cheatle, M. D., \& Rudy, J. W. Analysis of second-order odoraversion conditioning in neonatal rats: Implications for Kamin's blocking effect. Journal of Experimental Psychology: Animal Behavior Processes, 1978, 4, 237-249.

Clarke, J., Westbrook, R. F., \& Irwin, J. Potentiation instead of overshadowing in the pigeon. Behavioral and Neural Biology, $1979,25,18-29$.

Durlach, P. J., \& Rescorla, R. A. Potentiation rather than overshadowing in flavor-aversion learning: An analysis in terms of within-compound associations. Journal of Experimental Psychology: Animal Behavior Processes, 1980, 6, 175-187.

Holland, P. C. Second-order conditioning with and without unconditioned stimulus presentation. Journal of Experimental Psychology: Animal Behavior Processes, 1980, 6, 238-250.

Hull, C. L. Principles of behavior. New York: Appleton, 1943.

KAMIN, L. J. Attention-like processes in classical conditioning. In M. R. Jones (Ed.), Miami Symposium on the Prediction of Behavior: Aversive stimulation. Miami: University of Miami Press, 1968.

Rescorla, R. A. Pavlovian second-order conditioning: Studies in associative learning. Hillsdale, N.J: Erlbaum, 1980.

Rescorla, R. A. Simultaneous associations. In P. Harzem \& M. Zeiler (Eds.), Advances in analysis of behavior (Vol. 2). New York: Wiley, in press.

Rescorla, R. A., \& Cunningham, C. L. Within-compound flavor associations. Journal of Experimental Psychology: Animal Behavior Processes, 1978, 4, 267-275.

Rescorla, R. A., \& Durlach, P. J. Within-event learning in Pavlovian conditioning. In R. R. Miller \& N. S. Spear (Eds.), Information processing in animals: Memory mechanisms. Hillsdale, N.J: Erlbaum, in press.

Rescorla, R. A., \& Freberg, L. The extinction of withincompound flavor associations. Learning and Motivation, 1978, 9, 411-427.

Rusiniak, K., Hankins, W., Garcia, J., \& Brett, L. Flavorillness aversions: Potentiation of odor by taste in rats. Behavioral and Neural Biology, 1979, 25, 1-17.

Speers, M. J., Gillan, D. J., \& Rescorla, R. A. Withincompound associations in a variety of compound conditioning procedures. Learning and Motivation, 1980, 11, 135-149.

WAGNER, A. R. Expectancies and the priming of STM. In S. H. Hulse, H. Fowler, \& W. K. Honig (Eds.), Cognitive processes in animal behavior. Hillsdale, N.J: Erlbaum, 1978.

(Received for publication August 7, 1980; revision accepted November 20,1980 .) 